\title{
Effects of Wetland Plants on Nitrification and Denitrification Intensity in
}

\section{Sediment}

\author{
Chenfeng $\mathrm{He}^{1, \mathrm{a}}$, Hualin Wang ${ }^{1, \mathrm{~b}}$, Zhengda Duan ${ }^{1, \mathrm{c}}$, Zhongyu Wang ${ }^{1, \mathrm{~d}}$ and \\ Huayong Zhang ${ }^{1, e, *}$
}

\author{
${ }^{1}$ Research Center for Engineering Ecology and Nonlinear Science, North China Electric Power \\ University, Beijing 102206, China \\ arechercheramour@ncepu.edu.cn, ${ }^{\text {b}} 1162211052 @$ ncepu.edu.cn, ${ }^{c} 1162211051 @$ ncepu.edu.cn, \\ dzhy_wang@ncepu.edu.cn, ebjecology@gmail.com
}

Keywords: aquatic plant; wetland; sediment; nitrification and denitrification intensity

Abstract. By comparing the nitrification and denitrification intensity in sediments of different aquatic plant populations in Balihe Lake wetland, the main factors influencing sediment nitrification and denitrification intensity under different water depths as well as different aquatic plant populations were discussed. The results showed that the denitrification intensity in the sediments grown by phragmites australis, typha orientalis and nelumbo nucifera populations was mainly affected by the dissolved oxygen (DO) content. With the water depth increased, the DO content decreased and the denitrification intensity increased. The nitrification intensity was mainly affected by water temperature (WT), the higher the temperature was, the greater the nitrification intensity became. The sediment grown by phragmites australis, typha orientalis and nelumbo nucifera populations showed better TN removal efficiency in the wetland, at the $0.5 \mathrm{~m}$ water depth, the TN removal efficiency rank was phragmites australis > typha orientalis > nelumbo nucifera, when the water depth is larger $(1 \mathrm{~m})$, the removal efficiency rank was nelumbo nucifera $>$ typha orientalis > phragmites australis.

\section{Introduction}

Wetland, as the most biodiverse ecological landscape in nature, plays an important role in maintaining the ecological balance of nature [1]. Nitrogen is a biogenic factor that directly affects the primary productivity of wetlands. A large number of anaerobic, aerobic and facultative microflora are present on the surface of wetland sediment and the plant root surfaces, participating in nutrient cycling and improving redox conditions to improve water quality. It's been proved that nitrification and denitrification are the main ways to remove nitrogen from wetlands, which are often affected by climate, plant species and other factors [2]. And there are few researches on the influencing factors of nitrification/denitrification in different wetland plants under different water depths.

In this research, the main influencing factors of nitrification intensity and denitrification intensity of wetland sediments under different water depths were studied through field sampling and analysis. The effects of wetland plants on total nitrogen removal under different water depths were discussed, providing theoretical support for the construction of constructed wetlands. 


\section{Research Area and Methods}

The study area Balihe Lake is located in the west of Anhui Province, with geographic coordinates of longitude $116^{\circ} 01^{\prime} \sim 116^{\circ} 38^{\prime}$, latitude $32^{\circ} 54^{\prime} \sim 32^{\circ} 57^{\prime}$. The Balihe basin belongs to the subtropical and semi-humid monsoon climate, the annual average rainfall is $965.6 \mathrm{~mm}$; the average annual temperature is $15.1^{\circ} \mathrm{C}$; the frost-free period is 221 days; the sunshine is $2213.3 \mathrm{~h}$; and the evaporation is $920.5 \mathrm{~mm}$. In August, 2016, field surveys of the Balihe wetland were conducted. Sediment and water samples in the area of phragmites australis, nelumbo nucifera, typha orientalis and open water were collected at water depths of $0.5 \mathrm{~m}$ and $1 \mathrm{~m}$. The sediment samples were immediately sent to the laboratory to determine the nitrification and denitrification rate. The DO, WT and $\mathrm{pH}$ at the sampling site were measured on site using the YSI-Professional Plus Portable Water Quality Analyzer. After the sludge was centrifuged, the sediment interstitial water was collected and its $\mathrm{TN}, \mathrm{NO}_{3}{ }^{-}-\mathrm{N}$ and $\mathrm{NH}_{4}{ }^{+}-\mathrm{N}$ were measured.

Nitrification and denitrification intensity were determined according to Wang et al. [3]. TN was measured through Potassium persulfate digestion-UV spectro photometry, $\mathrm{NH}_{4}{ }^{+}-\mathrm{N}$ was measured through Nessler's reagent photometry, $\mathrm{NO}_{3}{ }^{-} \mathrm{N}$ was measured through sulfamic acid catalytic method.

\section{Results}

Sediment samples of $0.5 \mathrm{~m}$ and $1 \mathrm{~m}$ depths near the roots of phragmites australis, typha orientalis and nelumbo nucifera at the edge of wetlands were collected, and their nitrification and denitrification intensity were measured. The test results are shown in Fig. 1.
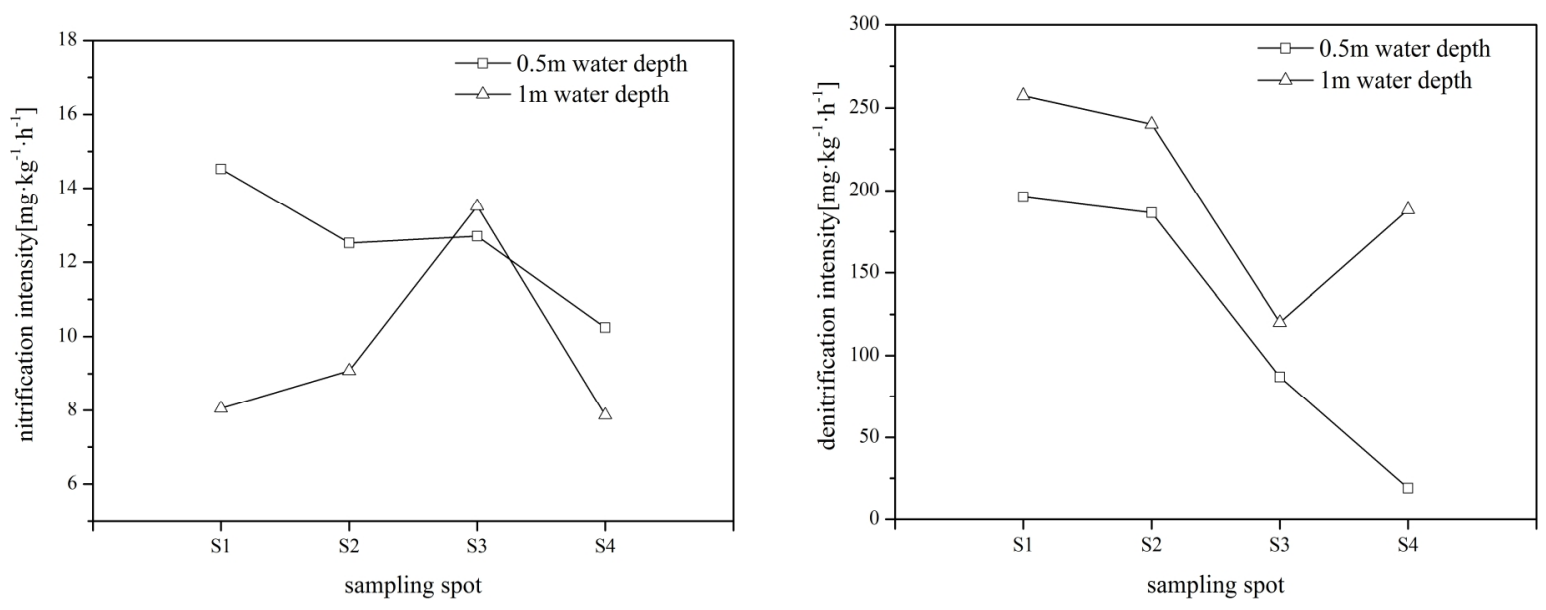

Fig.1 Nitrification and denitrification intensity in sediments grown by different plants. (The Abscissa values refer to different sampling spots, S1 S4 respectively represents spots grown by phragmites australis, nelumbo nucifera, typha orientalis and no plants)

The water depth (WD), WT, $\mathrm{pH}$ and $\mathrm{DO}$ at the sampling point of wetland sediment were measured on site, and the $\mathrm{TN}, \mathrm{NO}_{3}{ }^{-}-\mathrm{N}$ and $\mathrm{NH}_{4}{ }^{+}-\mathrm{N}$ in the sediment interstitial water were measured in the laboratory. The results are shown in Table 1. 
Table 1 Physical and chemical indexes of sediment grown by different plants

\begin{tabular}{cccccccc}
\hline Sample spot & $\begin{array}{c}\mathrm{WD} \\
{[\mathrm{m}]}\end{array}$ & $\begin{array}{c}\mathrm{WT} \\
{[\square]}\end{array}$ & $\mathrm{pH}$ & $\begin{array}{c}\mathrm{DO} \\
{\left[\mathrm{mg} \cdot \mathrm{L}^{-1}\right]}\end{array}$ & $\begin{array}{c}\mathrm{TN} \\
{\left[\mathrm{mg} \cdot \mathrm{L}^{-1}\right]}\end{array}$ & $\begin{array}{c}\mathrm{NO}_{3}{ }^{-}-\mathrm{N} \\
{\left[\mathrm{mg} \cdot \mathrm{L}^{-1}\right]}\end{array}$ & $\begin{array}{c}\mathrm{NH}_{4}{ }^{+}-\mathrm{N} \\
{\left[\mathrm{mg} \cdot \mathrm{L}^{-1}\right]}\end{array}$ \\
\hline \multirow{2}{*}{ phragmites australis } & 0.5 & 31.6 & 7.20 & 2.42 & 1.41 & 0.56 & 0.61 \\
typha orientalis & 1 & 31.5 & 7.33 & 0.93 & 2.11 & 1.16 & 0.60 \\
nelumbo nucifera & 0.5 & 31.5 & 7.23 & 1.19 & 1.84 & 1.23 & 0.25 \\
open water & 1 & 31.4 & 7.13 & 0.24 & 2.03 & 1.23 & 0.45 \\
& 0.5 & 31.6 & 7.19 & 1.40 & 2.09 & 1.29 & 0.48 \\
& 1 & 31.8 & 7.20 & 1.83 & 0.84 & 0.49 & 0.28 \\
& 1 & 31.8 & 7.22 & 1.57 & 2.22 & 1.15 & 0.64 \\
\hline
\end{tabular}

\section{Analysis and Discussion}

Nitrification Intensity of Sediment Grown by Different Wetland Plant Populations. As shown in Fig. 1, the nitrification intensities of the sediment in the phragmites australis and typha orientalis population and open water were higher than those in the smaller water depth group. Under the condition of the nelumbo nucifera population, the nitrification intensity of the sediment was lower than that under the larger water depth. The effect of temperature on the nitrification of wetland sediment is very obvious. Marife et al. found that the change of total nitrification rate in wetland was positively correlated with temperature $(\mathrm{r}=0.55, \mathrm{P} \leq 0.05)$ [4]. The effect of $\mathrm{pH}$ on nitrification is also very significant. Nitrification under highly acidic soil conditions will be inhibited and autotrophic nitrifying bacteria may be more suitable to grow at a $\mathrm{pH}$ of $6.6-8.0$ or higher. $\mathrm{Yu}$ et al. found that the nitrification rate of wetland soil had a significant positive correlation with $\mathrm{pH}$ [5]. The research of Wang et al. revealed that salinity and $\mathrm{pH}$ had the most significant effect on the nitrification of sediments, higher salinity and lower $\mathrm{pH}$ significantly inhibited the nitrification process [6].

Denitrification Intensity of Sediment Grown by Different Wetland Plant Populations. As can be seen in Fig. 2, the denitrification intensities of sediment in the phragmites australis, typha orientalis, nelumbo nucifera populations and open water under larger water depth conditions were all higher than those in the lower water depth. In this study, except for the nelumbo nucifera population, the water temperature for each plant populations and open water zone in the experimental group of $1 \mathrm{~m}$ water depth was lower than that of the $0.5 \mathrm{~m}$ group, while the DO showed the opposite tendency. Studies have shown that denitrification can be carried out in a wide temperature range $\left(5 \sim 70^{\circ} \mathrm{C}\right)$ and enhance with the increase of temperature, but it will be inhibited when the temperature is too high or too low [7]. The $\mathrm{N}_{2} \mathrm{O} / \mathrm{N}_{2}$ ratio of denitrification products is mainly affected by $\mathrm{pH}$ [8]. When $\mathrm{pH}$ was $<6$, production of $\mathrm{N}_{2}$ was inhibited and $\mathrm{N}_{2} \mathrm{O}$ was the main product because low $\mathrm{pH}$ inhibited the activity of $\mathrm{N}_{2} \mathrm{O}$ reductase, therefore increasing the proportion of $\mathrm{N}_{2} \mathrm{O}$ in the product [9]. Since denitrification is a microbial process performed under anaerobic conditions, the effect of moisture conditions on denitrification is acted indirectly by affecting aeration and $\mathrm{O}_{2}$ partial pressure. 
Nitrogen Removal Efficiency. Regarding the TN concentration in open water area as a standard, the TN removal efficiency affected by each plant population was calculated, which can be found in Fig. 2. When the water depth was $0.5 \mathrm{~m}$, the TN removal efficiency rank of each plant population revealed as phragmites australis > typha orientalis $>$ nelumbo nucifera. When the water depth was $1 \mathrm{~m}$, TN removal efficiency rank of all plant populations revealed as nelumbo nucifera > typha orientalis > phragmites australis. In general, nitrification and denitrification in constructed wetlands are the most important nitrogen removal mechanism. Ammonia volatilization is negligible when the $\mathrm{pH}$ is less than 7.5, but significant at $\mathrm{pH}$ values above 9.3. Nitrogen removal in constructed wetlands for treatment of domestic sewage mainly depends on the nitrification and denitrification of microorganisms [10]. In this study, TN removal efficiency and nitrification intensity showed the same trend when wetland plant populations exist.

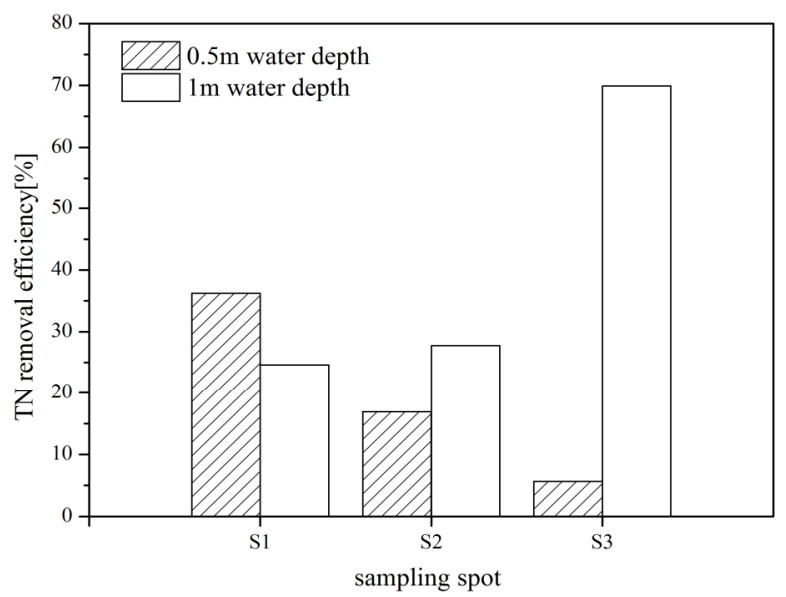

Fig.2 Influence of different plants on nitrogen removal efficiency (The Abscissa values refer to different sampling spots, S1 S3 respectively represents spots grown by phragmites australis, nelumbo nucifera, typha orientalis)

\section{Conclusions}

In the wetland studied, the nitrification intensities of sediments in phragmites australis, typha orientalis and nelumbo nucifera population were mainly affected by water temperature. The higher the temperature was, the greater the nitrification intensity became. The denitrification intensity in the sediments grown by phragmites australis, typha orientalis and nelumbo nucifera population was mainly affected by the DO content. The higher the water depth was, the lower the DO content and the greater the denitrification intensity became. The phragmites australis, typha orientalis and nelumbo nucifera population showed better TN removal efficiency. When the water depth was lower $(0.5 \mathrm{~m})$, the removal efficiency rank was phragmites australis $>$ typha orientalis $>$ nelumbo nucifera. When water depth was larger $(1 \mathrm{~m})$, the removing efficiency rank was nelumbo nucifera $>$ typha orientalis > phragmites australis. Therefore, in the construction and restoration of wetlands , the combination of phragmites australis and typha orientalis in the shallow water with nelumbo nucifera in the deeper water can be chosen to achieve better operation effect. Besides, other types of aquatic plants need further study.

\section{Acknowledgements}

The authors would like acknowledge with great appreciation for the support provided by the Chinese Major Science and Technology Program for Water Pollution Control and Treatment (No. 
2015ZX07204-007, No. 2015ZX07203-011), and the Fundamental Research Funds for the Central Universities (No. 2017MS055).

\section{References}

[1] W.J. Mitsch, S.M. Nedrich and S.K. Harter et al.: Sedimentation in created freshwater riverine wetlands: 15 years of succession and contrast of methods. Ecological Engineering Vol. 72 (2014), p. 25-34.

[2] S.Y. Lu, X.C. Jin and G. Yu, et al.: Nitrogen removal mechanism of constructed wetland. Acta Ecologica Sinica, Vol. 26 (2006), p. 2670-2677.

[3] X.J. Wang and R.S. Zhang: Study on intensity of microorganism nitrification and denitrification in constructed wetlands. Acta Scientiae Circumstantiae Vol. 26 (2006), p. 225-229.

[4] D.C. Marife, R.S. Ronald and L.S. William: Spatial and seasonal variation of gross nitrogen transformations and microbial biomass in Northeastern US grassland. Soil Biology \& Biochemistry Vol. 34 (2002), p. 445-457.

[5] Y.U. Luo, M. Gao and C.I. En, et al.: Study on the characteristics of mineralization and nitrification in different cultivation modes. Ecology \& Environmental Sciences Vol. 19 (2010), p. 733-738.

[6] Y.P. Wang, L.L. Wang and Q.S. Li, et al.: Study on nitrification and impact factors in Pearl River estuarine wetlands. Ecological Science Vol. 31 (2012), p. 330-334.

[7] J. Huang, S.H. Wang and L. Yan, et al.: Intensity of nitrification and denitrification in subsurface-flow constructed wetlands. Environmental Science Vol. 28 (2007), p. 1965.

[8] Simek M. and J. E. Cooper: The influence of soil $\mathrm{pH}$ on denitrification: progress towards the understanding of this interaction over the last 50 years. European Journal of Soil Science Vol. 38 (2014), p. 690-692.

[9] X.Z. Wang, W. Sun and W.P. Yin, et al.: Effects of $\mathrm{pH}$ on $\mathrm{N}_{2} \mathrm{O}$ emission from nitrification in acid soil. Soils Vol. 38 (2009), p. 962-967.

[10] S.Y. Lu, X.C. Jin and G. Yu: Nitrogen removal mechanism of constructed wetland. Acta Ecologica Sinica Vol. 26(2006), p. 2670-2677. 